\title{
Meta-Analysis Approach identifies Candidate Genes and associated Molecular Networks for Type-2 Diabetes Mellitus
} Axel Rasche*1, Hadi Al-Hasani ${ }^{2}$ and Ralf Herwig ${ }^{1}$

\author{
Address: ${ }^{1}$ Max-Planck-Institute for Molecular Genetics, Department of Vertebrate Genomics, Ihnestrasse 63-73, D-14195 Berlin, Germany and \\ ${ }^{2}$ German Institute for Human Nutrition, Potsdam-Rehbrücke, Arthur-Scheunert-Allee 114-116, D-14558 Nuthetal, Germany \\ Email: Axel Rasche* - rasche@molgen.mpg.de; Hadi Al-Hasani - al-hasani@dife.de; Ralf Herwig - herwig@molgen.mpg.de \\ * Corresponding author \\ Published: 30 June 2008 \\ BMC Genomics 2008, 9:310 doi:10.1186/|47|-2164-9-310 \\ Received: 21 November 2007 \\ Accepted: 30 June 2008 \\ This article is available from: http://www.biomedcentral.com/I47I-2/64/9/3/0 \\ (c) 2008 Rasche et al; licensee BioMed Central Ltd. \\ This is an Open Access article distributed under the terms of the Creative Commons Attribution License (http://creativecommons.org/licenses/by/2.0), \\ which permits unrestricted use, distribution, and reproduction in any medium, provided the original work is properly cited.
}

\begin{abstract}
Background: Multiple functional genomics data for complex human diseases have been published and made available by researchers worldwide. The main goal of these studies is the detailed analysis of a particular aspect of the disease. Complementary, meta-analysis approaches try to extract supersets of disease genes and interaction networks by integrating and combining these individual studies using statistical approaches.
\end{abstract}

Results: Here we report on a meta-analysis approach that integrates data of heterogeneous origin in the domain of type-2 diabetes mellitus (T2DM). Different data sources such as DNA microarrays and, complementing, qualitative data covering several human and mouse tissues are integrated and analyzed with a Bootstrap scoring approach in order to extract disease relevance of the genes. The purpose of the meta-analysis is two-fold: on the one hand it identifies a group of genes with overall disease relevance indicating common, tissue-independent processes related to the disease; on the other hand it identifies genes showing specific alterations with respect to a single study. Using a random sampling approach we computed a core set of 213 T2DM genes across multiple tissues in human and mouse, including well-known genes such as Pdk4, Adipoq, Scd, Pik3rl, Socs2 that monitor important hallmarks of T2DM, for example the strong relationship between obesity and insulin resistance, as well as a large fraction (128) of yet barely characterized novel candidate genes. Furthermore, we explored functional information and identified cellular networks associated with this core set of genes such as pathway information, protein-protein interactions and gene regulatory networks. Additionally, we set up a web interface in order to allow users to screen T2DM relevance for any - yet non-associated - gene.

Conclusion: In our paper we have identified a core set of 2/3 T2DM candidate genes by a metaanalysis of existing data sources. We have explored the relation of these genes to disease relevant information and - using enrichment analysis - we have identified biological networks on different layers of cellular information such as signaling and metabolic pathways, gene regulatory networks and protein-protein interactions. The web interface is accessible via http://t2dmgeneminer.molgen.mpg.de. 


\section{Background}

Type-2 diabetes mellitus (T2DM) is a rapidly increasing disease with more than 170 million afflicted persons worldwide (constituting more than $90 \%$ of all diabetic patients). T2DM poses a huge burden for the health care systems and is, thus, subject to intensive biomedical research. T2DM is a multigenic disease involving a high number of susceptibility genes and causes alteration of an entire network of genes. Several environmental and nutritional risk factors have been identified for T2DM the most relevant being obesity where multiple molecular mechanisms have been proposed to link obesity to insulin resistance and beta cell failure [1]. Increased availability of food and reduced physical activity as a consequence of modern lifestyle are the main drivers for an anticipated epidemic increase in T2DM patients in the next years.

In the pathopysiology of T2DM, impaired insulin sensitivity and glucose intolerance are early phenomena, leading to hyperglycemia, hyperlipidemia and, eventually, to a failure of pancreatic beta cells to produce and secrete a sufficient amount of insulin. However, most genes and their associated molecular network contributing to the onset and course of the disease are yet unknown.

Genetic variation in the context of diabetes has already been extensively studied, leading to numerous candidate genes. Studies on transgenic and knock-out mice have been valuable to dissect the regulatory network of genes implicated in insulin action and body weight control $[2,3]$, however, monogenic variants contribute only to a minority of T2DM cases. In contrast, the polygenic nature of T2DM is now well established and several polygenic mouse models including NZO, BTBR etc. have been studied to analyze diabetes susceptibility on a more complex genetic background [4]. Linkage analyses have shown that several quantitative trait loci interact with each other and with the environment to elicit obesity syndromes that are potentially diabetic. Several recent genome-wide association studies have identified novel candidate genes for T2DM but the effect of these variants on disease susceptibility is generally low, with odds ratios mostly around 1.5 [5-11].

Multiple studies on the transcriptome level have been performed that emphasize the diversity of the disease and the complex pathophysiological interactions between different tissues, including fat, muscle, liver, pancreatic beta cells and brain [1]. In several human studies, tissue biopsies from diabetic and normoglycaemic individuals have been profiled $[12,13]$. In mouse studies differences in diet or mouse strains have been used to identify distinct expression profiles [14-16]. Complementary ChIP-onChip studies reveal the associated gene regulatory network of important transcription factors (TFs) active in the rele- vant tissues $[17,18]$. In the context of the onset of diabetes, several studies on the proteomic level have revealed differential expression of intracellular proteins as well as of secretory proteins in adipose tissue [19]. Despite the availability of these large amounts of data, their common content as well as their specific differences, in particular in gene sets between human and rodent studies, has not yet been systematically evaluated.

The goal of this meta-analysis approach is to generate additional value by combining the above-mentioned individual studies and by extracting consistent information. Several meta-analyses studies have been previously applied within other disease domains, such as cancer [20] or Alzheimer [21] using different types of data. With respect to T2DM some recent approaches have been published: In Tiffin et al. several computational prediction methods have been combined in order to identify a common set of T2DM genes [22]. The authors assessed the accordance of the prediction methods resulting in a candidate gene list of 99 different genes. For type-1 diabetes mellitus a web-resource has been set up that tracks the expression behavior of genes in several tissues [22]. Liu et al. have applied enrichment analysis to previously defined gene sets and protein-protein interactions using data from different species and tissues from the Diabetes Genome Anatomy Project [23] and identified a subnet of insulin signaling proteins and nuclear receptors [24]. In contrast to Rhodes et al., Sun and Liu et al. our approach is not limited to transcriptome studies $[7,24,25]$. We have accumulated data from different levels of molecular interaction such as genetic information using knock-out mice and single nucleotide polymorphisms (SNPs), gene regulatory and gene expression information as well as information on protein signaling and protein interactions. In order to reduce technical bias of transcriptome measurements we restricted this data type to experiments that were performed on the Affymetrix GeneChip platform. Similar to Liu et al., we combined the relevant tissues such as liver, muscle, adipose tissue and pancreas [24] since T2DM has physiological consequences in several parts of the body. Furthermore, a more global view on T2DM has been achieved by involving mouse as well as human data because the available mouse models address specific aspects of the disease and it is unclear, whether these mice have diabetes for the same reason as humans do.

Using a Bootstrap [26] scoring approach we computed a core set of 213 genes that show significant disease relevance in the data sets under study. Here, we used the gene expression profiles along with qualitative data comprising literature, genetic and proteomic sources. Besides known genes our approach exhibits a large fraction (128) of yet barely characterized novel candidate genes. These genes have been further validated in the functional context of 
networks and exhibit high potential for understanding pathways and pathway crosstalk associated with T2DM. By applying gene set enrichment analyses we inferred the deranged parts of the physiology using gene ontology terms [27], common pathway resources [28-30] and information on the associated gene regulatory network $[17,18,31]$.

The meta-analysis approach is generic and can be used as a template for studies in other disease domains. It has been completely implemented in the software platform $\mathrm{R}$ using the BioConductor package collection [32-34]. Our T2DM-GeneMiner web resource [35] allows the user to access the information that was gathered and to assess diabetic potential for any human or mouse gene of interest.

\section{Results}

We present the identification of the T2DM candidate genes, the comparison to previously published T2DM gene lists and results from association and linkage studies as well as the identification of associated molecular networks on different levels.

\section{Annotation, preprocessing and categorization of data} We used Ensembl (version 39) as the annotation reference database. Homology between human and mouse genes was derived via BioMart. The total number of genes under study comprises 15,277 Ensembl mouse genes representing the union of the homologue genes from all data sources. An overview about the T2DM specific datasets is given in Table 1.

Several of the available resources are based on microarrays. Each individual microarray study was normalized using the GC RMA method of the R/BioConductor package $[33,34,36]$. Recently, it has been reported that the remapping of the oligoprobes, as an alternative to the annotation given by the chip provider, enhances data analysis to a significant extent [37]. Using this mapping we indeed observe differences in annotation resulting from recent changes in genome annotation. Annotation comparisons showed improvement of reproducibility and specificity (data not shown). Re-annotation affects the main fraction of genes, for example in the remapped Mouse Genome U74A version 2 platform the top ten genes of our candidate list are represented by oligoprobe sets of 8 to 15 probes ( 11 with annotation of the chip provider) with an average of 13 probes (Serpina1 a 11 probes, Ybx1 8, Pdk4 16, Cstb 14, Adipoq 15, Agt 14, Lgals1 11, Serpine2 15, Mt2 10, Gpi1 16 probes).

\section{Identification of T2DM candidate genes - generality versus specificity}

Numerical scores were computed for all genes in each individual study, the scores were summarized and the summarized scores were compared against a random sample at the 99.9 percentile as described in Materials \& Methods. This procedure determines a cut-off score value of 3.05 and identifies a set of 213 genes with a score exceeding this cut-off.

Randomly, we would expect 15 out of the 15,277 genes to exceed the threshold. Cutting at the 99 percentile results in 943 genes (expecting 153 by chance), cutting at the 98 , 97, 96 and 95 percentiles would result in 1352, 1587, 1792 and 1972 selected genes (305, 458, 611 and 764 randomly expected genes). Thus, the ratio of detected vs. expected significant genes increases with percentile of the random sample from 2.6 to 14.2 , indicating a necessary precondition for the validity of our selection procedure [see Figure 1 in Additional file 1]. Since we have analyzed data from multiple tissues in human and mouse, it is likely that for some cases an individual experiment is dominating the score, for example, if the gene is active only in a single tissue. In order to identify those genes we have computed an entropy-based numerical criterion (see

Table I: Overview on the datasets used for the T2DM meta-analysis approach.

\begin{tabular}{|c|c|c|c|c|c|}
\hline Data set & Category & Species & Tissue & Study research question & Reference \\
\hline StumvollGoldstein 2005 & qualitative & human & & medical review about T2DM & {$[\mathrm{l}]$} \\
\hline DeanMcEntyre2004 & qualitative & human & & medical review about selected candidate genes & {$[48]$} \\
\hline OMIM & qualitative & human & & medical review about T2DM & {$[44]$} \\
\hline PubMedGeneRIF & qualitative & $\begin{array}{l}\text { human/ } \\
\text { mouse }\end{array}$ & & text mining in the $\mathrm{NCBI}$ geneRIF & [49] \\
\hline KOmiceJAX & qualitative & mouse & & mouse models with phenotype T2DM & {$[2]$} \\
\hline NandiAccili2004 & qualitative & mouse & & mouse models with phenotype "Insulin Resistance" & [3] \\
\hline ChenHess2005 & qualitative & rat & fat & secretory proteins in adipose tissue & {$[19]$} \\
\hline MoothaGroop2003 & quantitative & human & muscle & $\begin{array}{l}\text { patients with T2DM/impaired glucose tolerance } \\
\text { and controls }\end{array}$ & {$[13]$} \\
\hline GuntonKahn2005 & quantitative & human & pancreas & patients with T2DM versus controls & {$[12]$} \\
\hline LanAttie2003 & quantitative & mouse & fat/muscle/liver/pancreas & diabetic mice versus controls & {$[15]$} \\
\hline BiddingerKahn2005 & quantitative & mouse & fat/muscle/liver & diabetic mice versus controls & {$[14]$} \\
\hline NadlerAttie2000 & quantitative & mouse & fat & diabetic mice with different level of hyperglycaemia & {$[16]$} \\
\hline
\end{tabular}


Materials \& Methods). Entropy is high if many experiments contribute equally to the overall score, it is low if a single (or few) experiment accounts for a large fraction of the score. For example, the gene Serpinalb has the top score $(7.9$, rank $1 / 15,277)$ in our study. This is due to a very high fold-change in a single experiment; consequently, entropy is low $(1.17$, rank $4,590 / 15,277)$. In contrast, other genes show more consistent alterations across many different studies, for example Pdk4 (6.7, rank 3/ $15,277)$ indicated by higher entropy $(3.0,167 / 15,277)$. Differential expression of Pdk4, a major regulator of glucose metabolism, has been found in fat, pancreatic islets and skeletal muscle but not in liver.

The thirty genes with highest scores are listed in Table 2 [The entire candidate list is given in Additional file 2].

Adiponectin (Adipoq) has a score of 6.1 (rank 5/15,277) and the high entropy indicates a consistent behavior across data sets. Adipoq is a hormone from adipocytes that modulates insulin sensitivity and thus regulates glucose and lipid metabolism and energy homeostasis. Expression of Adipoq is reduced in obesity, certain genotypes are associated with increased risk of T2DM in humans [38]. The protein is secreted from fat tissue and has insulin-sensitising and anti-inflammatory properties. Additionally, we find strong changes in the expression in muscle both in human and mice. Adipoq is an oxidative regulator. The systemic oxidative stress causes the metabolism to share the burden from fat to muscle [39]. Adipoq is also responsible for the crosstalk between the three KEGG pathways 'PPAR signaling', 'Adipocytokine signaling' and 'type II diabetes mellitus'. It has been tested for transcriptional regulation but no binding to the TFs under study could be detected. A negative regulation has been described for Tnf that has not been tested in the underlying studies.

Pdk4 phosphorylates and inhibits pyruvate dehydrogenase complex thereby contributing to the regulation of glucose metabolism. Expression of this gene is regulated by glucocorticoids, retinoic acid and insulin. This is in accordance with a consistent differential expression in fat,

Table 2: Top thirty T2DM candidate genes (out of 213).

\begin{tabular}{|c|c|c|c|c|c|c|}
\hline SourceName & mgi_symbol & entrezgene & refseq_dna & HUGO & Score & Entropy \\
\hline ENSMUSG0000007। I 78 & Serpina la ; Serpina lb & 20701 & NM_009244 & SERPINAI & 7.899 & 1.167 \\
\hline ENSMUSG00000028639 & Ybxl & 22608 & $\begin{array}{l}\text { XR_003217; XR_003023; XR_001819; } \\
\text { NM_011732 }\end{array}$ & & 7.065 & 2.484 \\
\hline ENSMUSG00000019577 & Pdk4 & 27273 & NM_013743 & PDK4 & 6.668 & 2.993 \\
\hline ENSMUSG00000005054 & Cstb & 13014 & NM_007793 & CSTB & 6.11 & 2.746 \\
\hline ENSMUSG00000022878 & Adipoq & 11450 & NM_009605 & ADIPOQ & 6.082 & 3.043 \\
\hline ENSMUSG00000031980 & Agt & 11606 & NM_007428 & AGT & 5.912 & 2.052 \\
\hline ENSMUSG00000068220 & Lgals I & 16852 & NM_008495 & LGALSI & 5.895 & 1.85 \\
\hline ENSMUSG00000026249 & Serpine2 & 20720 & NM_009255 & SERPINE2 & 5.894 & 2.49 \\
\hline ENSMUSG00000031762 & Mt2 & 17750 & NM_008630 & MTIX & 5.67 & 2.72 \\
\hline ENSMUSG00000036427 & Gpil & $|475| ; 676974$ & NM_008I55 & & 5.598 & 1.619 \\
\hline ENSMUSG0000003707I & Scdl & 20249 & NM_009I27 & SCD & 5.553 & 2.358 \\
\hline ENSMUSG00000025453 & Nnt & 18115 & NM_0087I0 & NNT & 5.539 & 2.307 \\
\hline ENSMUSG00000016194 & Hsdl Ibl & 15483 & NM_008288 & HSDIIBI & 5.452 & 2.489 \\
\hline ENSMUSG00000026628 & Atf3 & 11910 & NM_007498 & ATF3 & 5.446 & 2.676 \\
\hline ENSMUSG00000023087 & Corn4l & 12457 & NM_009834 & CCRN4L & 5.434 & 2.333 \\
\hline ENSMUSG00000021190 & Lgmn & 19141 & NM_0III75 & LGMN & 5.225 & 2.588 \\
\hline ENSMUSG00000061780 & Cfd & 11537 & NM_0I3459 & CFD & 5.158 & 2.429 \\
\hline ENSMUSG00000029657 & Hspl IO & 15505 & NM_0I3559 & HSPHI & 5.14 & 2.438 \\
\hline ENSMUSG00000025006 & Sorbs I & 20411 & $\begin{array}{l}\text { NM_I78362; NM_00I034964; } \\
\text { NM_00I034963; NM_001034962; } \\
\text { NM_009166 }\end{array}$ & SORBSI & 5.092 & 2.639 \\
\hline ENSMUSG00000029309 & Sparcll & 13602 & NM_010097 & SPARCLI & 5.024 & 2.013 \\
\hline ENSMUSG0000002498I & Acsl5 & 433256 & NM_027976 & ACSL5 & 4.912 & 2.868 \\
\hline ENSMUSG000000320I8 & Sc5d & 235293 & NM_I72769 & SC5DL & 4.879 & 1.622 \\
\hline ENSMUSG00000035385 & $\mathrm{Ccl} 2$ & 20296 & NM_0II333 & & 4.856 & 1.764 \\
\hline ENSMUSG00000041417 & Pik3rl & 18708 & NM_00I024955 ; NM_0II 085 & PIK3RI & 4.852 & 3.008 \\
\hline ENSMUSG00000026003 & Acadl & 11363 & NM_00738I & ACADL & 4.839 & 2.911 \\
\hline ENSMUSG000000068I8 & Sod2 & 20656 & NM_0I367I & SOD2 & 4.746 & 3.127 \\
\hline ENSMUSG00000020027 & Socs2 & 216233 & NM_007706 & SOCS2 & 4.682 & 2.57 \\
\hline ENSMUSG00000026687 & Aldh9al & 56752 & NM_019993 & ALDH9AI & 4.666 & 2.467 \\
\hline ENSMUSG00000020593 & Lpin I & 14245 & NM_I 72950 ; NM_0I5763 & LPINI & 4.639 & 2.285 \\
\hline ENSMUSG00000027690 & Sic2a 2 & 20526 & NM_03II 97 & $\mathrm{SLC} 2 \mathrm{~A} 2$ & 4.617 & 2.461 \\
\hline
\end{tabular}


muscle and pancreatic islets resulting in high entropy. On the other hand, possible regulation of the gene by Hnf $4 a$ and Usf1 is reported in liver.

Hydroxysteroid (11-beta) dehydrogenase 1 (Hsd11b1, score 5.5, rank 13/15,277) is a critical enzyme for cortisol metabolism. Hsd11b1 is increased in obese subjects and transgenic mice over-expressing $H s d 11 b 1$ develop visceral obesity [40]. Inhibition of Hsd11b1 decreases blood glucose in hyperglycaemic mice. Selective antagonists are currently developed and tested as anti-obesity and antidiabetes drugs.

Scd1 (5.6, 11/15,277) is the rate-limiting enzyme in monounsaturated fatty acid synthesis. It has been shown to exert a critical role in hepatic lipogenesis and lipid oxidation. Scd1 knock-out mice are lean due to increased energy expenditure, show increased insulin sensitivity and are resistant to diet-induced obesity and liver steatosis.

Nicotinamide nucleotide transhydrogenase (Nnt, 5.5, 12/ $15,277)$ is a mitochondrial enzyme involved in proton transport into the mitochondrial matrix. Nnt was identified as a novel candidate gene in a quantitative trait locus for glucose intolerance [41]. Nnt has been recently shown to regulate insulin secretion in pancreatic beta cells. Nnt deficiency results in defective insulin secretion and inappropriate glucose homeostasis [42]. It has been proposed that Nnt detoxifies reactive oxygen species [43] implicating a possible role of Nnt in regulating ATP production in mitochondria and function of the ATP sensitive $\mathrm{K}+$ channel Kir6.2 (Kcnj11) in insulin producing beta cells.

For eighteen genes only limited functional information is available as a basis for assessing a possible relationship to T2DM: Ccrn4l, Serpina12, Htatip2, Mest, Pgcp, Tmsb4x, Angptl4, Mrpl33, Ndfip1, Yipf5, Tmem30a, Asnsd1, Oact5, Larp5, Thrsp, 1810015C04Rik, 2310003F16Rik, and 2610002J02Rik. High genetic variation is known for Pgcp in mouse. Serpina12, a target of $H n f 4 a$, is massively changed in liver and 1810015C04Rik in pancreatic islets. Using the entropy criterion we observe medium to high entropy in these genes, like in Ndfip1 (entropy 2.9), what points to the fact that high scoring of these genes was not due to single outlier experiments but that these genes are truly affected by the disease and, thus, exhibit a high potential for further functional experiments.

\section{T2DM-GeneMiner web tool}

In order to allow users to screen the disease potential of any given gene of interest we developed T2DM-GeneMiner, a web interface summarizing the results of our work (Figure 1, [35]). The user interface is shown for the wellknown Adipog and the resulting bar plots for two other genes, $P d k 4$ and $C f d$, with lower content of available infor- mation. The resource is searchable by gene or protein IDs (for example Ensembl ID or gene symbol). The score distribution is shown as a bar plot and, where available, functional information is displayed. The two rightmost bars show the entropy, indicating uniform or specific score distribution, and the score. The red line at the score bar indicates the cut-off.

\section{Overlap to previous predictions of T2DM genes}

From fourteen genes in the OMIM description of T2DM (Diabetes mellitus, noninsulin dependent, \#125853, [44]) five genes have a significant score in our study: Retn, Gpd2, Vegfa, Irs2 and Tcf2 (see Table 3). Retn represents an adipocytokine which has been implied to play roles in obesity, diabetes, and insulin resistance $[45,46]$. Interestingly, Retn is only deregulated in one of two studies involving adipose tissue. In contrast, differential expression for Irs2, Vegfa and Tcf2 was observed in pancreatic islets whereas Gpd2 did not show tissue-specific expression. Several previous studies have already published T2DM candidate lists allowing us to assess common content. The overlap to the list of the Diabetes Genome Anatomy Project [23], being also the source of some of the transcriptome data sets used for this meta-analysis [1214], results in a P-value of 9.9E-03. Using the same resource, with a less conservative selection of data sets, Liu et al. identified 82 genes related to insulin signaling with an overlap of seven genes to our candidate list containing several strongly connected proteins (see below) [24]. More selective is a review of sequencing candidates leading to a P-value of 5.28E-13 [47]. In Tiffin et al. 99 candidates were published as partial overlap of several electronic candidate prediction methods [22]. This results in a P-value of 1.9E-05 comparing it with our list (Figure 2 shows a Venn diagram of the absolute gene numbers). In summary, the T2DM candidate gene list includes a small amount of candidate genes from previous studies and, further, leads to an additional set of 191 genes not identified in the other studies. Subtracting those genes for which we have disease information from the incorporated reviews our approach identifies 128 novel T2DM candidate genes.

\section{Relation to monogenic mouse models for T2DM}

A variety of genetic studies have been performed in the last decades. At least nineteen genetically engineered mouse models with T2DM phenotype have been studied in detail $[2,3]$. Of those, five genes show a significant score in our meta-analysis: Slc2a4, Irs2, Ptpn1, Slc2a2 and Irs1. Consistent with previous reports, the insulin-regulated glucose transporter GLUT4 (Slc2a4) is down-regulated in the insulin resistant state in adipose tissue but not in skeletal muscle. Likewise, down-regulation of Irs 2 and the glucose transporter GLUT2 (Slc2a2) in pancreatic islets confirms previous reports and reflects deterioration of 

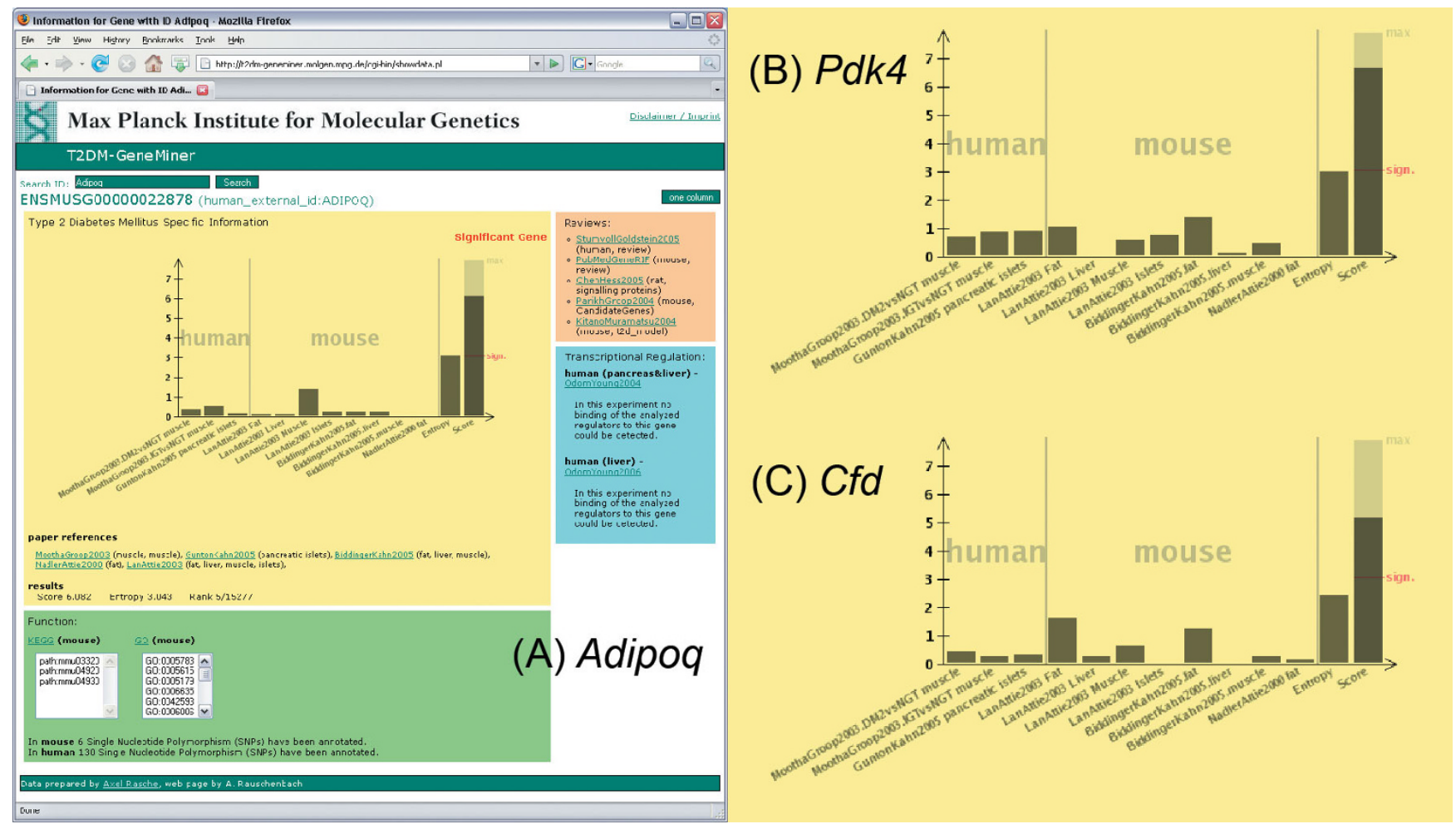

Figure I

Screen-shot of the web tool showing results on different genes with different amount of available information: (A) Adipoq, (B) Pdk4 and (C) Cfd.

beta cell function in the course of insulin resistance and diabetes.

On the other side $S l c 2 a 2$ is also changed in liver. Ptpn1 is expressed in all tissues showing only small fold-changes. Several genes from OMIM or KO-mice do not change at all on the expression level. This indicates that only the complete loss of the associated protein alters the system whereas the gene's expression is not altered in T2DM. For KO-mice we also see a strong tendency to genes only expressed in mice.

\section{Relation to human and rodent association and linkage studies}

Recently, a total of nine candidate genes for T2DM have been identified and replicated in humans through multi-

Table 3: Results for T2DM OMIM genes.

\begin{tabular}{|c|c|c|c|c|c|c|c|c|c|c|c|}
\hline SourceName & $\begin{array}{l}\text { Mgi } \\
\text { symbol }\end{array}$ & $\begin{array}{l}\text { Stumvoll } \\
\text { Goldstein } \\
2005\end{array}$ & $\begin{array}{l}\text { Dean } \\
\text { McEntyre } \\
2004\end{array}$ & OMIM & $\begin{array}{l}\text { PubMed } \\
\text { Gene RIF }\end{array}$ & $\begin{array}{l}\text { KO mice } \\
\text { Jax }\end{array}$ & $\begin{array}{l}\text { Nandi } \\
\text { Accili } 2004\end{array}$ & score & entropy & $\begin{array}{l}\text { significant } \\
\text { gene }\end{array}$ & $\begin{array}{l}\text { rank } \\
\text { (out of } \\
\text { I5,277) }\end{array}$ \\
\hline ENSMUSG000000I 2705 & Retn & & & $*$ & * & & & 4.597 & 2.106 & $*$ & 31 \\
\hline ENSMUSG00000026827 & Gpd2 & & & $*$ & & & & 4.452 & 2.88 & $*$ & 39 \\
\hline ENSMUSG0000002395I & Vegfa & & & $*$ & $*$ & & & 4.273 & 2.724 & $*$ & 52 \\
\hline ENSMUSG00000038894 & Irs2 & $*$ & & $*$ & $*$ & $*$ & & 3.907 & 2.112 & $*$ & 82 \\
\hline ENSMUSG00000020679 & Tcf2 & & $*$ & $*$ & $*$ & & & 3.175 & 1.605 & $*$ & 176 \\
\hline ENSMUSG0000004I798 & Gck & $*$ & $*$ & $*$ & $*$ & $*$ & & 3 & 1.585 & & 234 \\
\hline ENSMUSG00000029644 & $|p f|$ & $*$ & $*$ & $*$ & $*$ & $*$ & & 3 & 1.585 & & 234 \\
\hline ENSMUSG00000029556 & Tcfl & & $*$ & $*$ & $*$ & $*$ & & 3 & 1.585 & & 234 \\
\hline ENSMUSG00000040I36 & Abcc8 & $*$ & $*$ & $*$ & $*$ & & & 2.795 & 1.848 & & 325 \\
\hline ENSMUSG0000003470I & $\begin{array}{l}\text { Neurod5; } \\
\text { Neurod I }\end{array}$ & & $*$ & $*$ & $*$ & & & 2.393 & 1.48 & & 608 \\
\hline ENSMUSG000000I 7950 & Hnf4a & $*$ & $*$ & * & $*$ & & & 2.36 & 1.614 & & 642 \\
\hline ENSMUSG00000024985 & Tcf7I2 & & & $*$ & $*$ & & & 2.192 & 1.371 & & 811 \\
\hline ENSMUSG00000037370 & Enppl & & & $*$ & $*$ & & & 2.106 & 1.237 & & 918 \\
\hline ENSMUSG00000027223 & Mapk8ipl & & & $*$ & & & & I & 0 & & 3013 \\
\hline
\end{tabular}




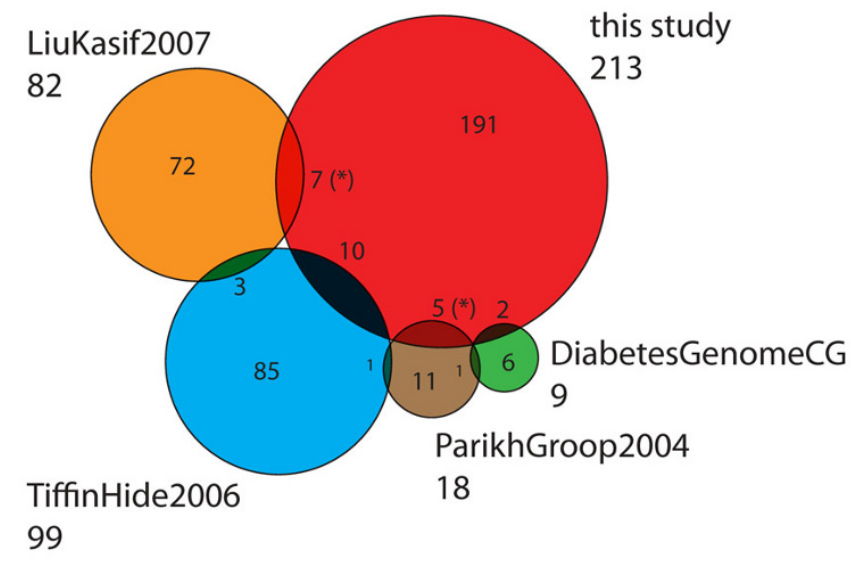

Figure 2

Venn diagram of candidate gene lists. Abbreviations relate to the following references: TiffinHide2006 [22], DiabetesGenomeCG [23], ParikhGroop2004 [47] and LiuKasif2007 [24]. One gene in TiffinHide2006 has been neglected for the count since no transcriptional information was available for that gene. (*) Two genes are counted twice because the intersection of LiuKasif2007 and our study shares those genes with ParikhGroop2004.

ple genome-wide association studies of common variants by using high-density SNP mapping approaches: Cdkal (score 0),Cdkn2a (score 0)/Cdkn2b (1.925, 1165/15277), Fto $(1.798,1364 / 15277)$, Hhex $(1.213,2456 / 15277)$, Igf2bp2 (0.855, 3555/15277), Kcnj11 (2, 1056/15277), Pparg (2.528, 500/15277), Slc30a8 (0.076, 8056/15277), and $T c f 7 l 2(2.192,811 / 15277)$ [5-11]. Interestingly, none of these genes shows a high score in our meta-analysis, although Pparg and Tcf7l2 are significant on the less restrictive 0.01 level. On the other hand, from the data we could infer that Fto and Hhex act in pancreatic islets indicated by the T2DM-GeneMiner result for these genes. Cdkal1 and Cdkn2a are not expressed in the transcriptional studies. These genes show very low expression levels or might be active in tissues not included in our study. Since our meta-analysis approach takes into account several data sets from DNA microarrays, our candidate genes have a bias towards transcripts whose expression is changed in the context of T2DM. Moreover, the gene variants from association studies may not result in altered gene expression and, for most SNPs found in association studies, there is a lack of functional information since the variation mostly occurs in non-coding regions of the genes. In order to correlate the T2DM genes with genetic variation we plotted the number of known SNPs for the genes [see Figure 2 in Additional file 1]. No general tendency to highly variable genes is observable. Two genes of the candidate list show high variation, Pgcp $(9,098$ SNPs) and Sorbs1 $(4,130)$. Particularly interesting is Pgcp,



Figure 3

Pathway crosstalk with respect to the T2DM candidate gene set. Pathways were derived from the KEGG database. Each pathway has been weighted according to the total disease score reflected by the size of the nodes. Only pathways with a total score $>20$ were selected for display. The thickness of the edges between the different pathway nodes reflects the overlap score derived from the sum of the scores of the overlapping genes. The graph was generated with the graphviz package [62].

because it has not been related to T2DM before and its functional role is also undetermined.

A further issue of our study was the chromosomal localization of the T2DM genes. The marker genes are scattered over the entire mouse genome [see Figure 3 in Additional file 1]. Using the hypergeometric distribution on local sliding windows across the chromosome we could identify significantly enriched chromosomal regions. However, none of these regions convinced since they are sparsely occupied. For example on chromosome 2 with 2,249 genes and 15 T2DM candidates, a window of 20 genes containing two T2DM candidates leads to a P-value of 0.007 . None of the windows of 20 genes contained 
Table 4: Overview about the network level, e.g. gene set, resources used in the meta-analysis approach.

\begin{tabular}{llllll}
\hline Resource & Species & Resource content & Version & No. gene sets & Reference \\
\hline KEGG & mouse & pathway & 09.01 .2007 & 182 & {$[29]$} \\
Reactome & human & pathway & 19 & 691 & {$[28]$} \\
BioCyc & human & pathway & 9.1 & 169 & {$[30]$} \\
OdomYoung2004 & human & study of selected TF in liver and pancreas & publication & 6 & {$[18]$} \\
OdomYoung2006 & human & study of selected TF in liver & publication & 6 & 187 \\
TransFac & mouse & sequence motifs for TF & 10.2 & 187 & {$[31]$} \\
GO molecular function & mouse & ontology & Ensembl 4I & 987 & {$[56,57]$} \\
GO cellular component & mouse & ontology & Ensembl 4I & 350 & {$[56,57]$} \\
GO biological process & mouse & ontology & Ensembl 4l & 1977 & {$[56,57]$} \\
\hline
\end{tabular}

more than three candidates. Rather conversely, we observe that T2DM affects a wide range of physiological phenomena spanning loci in the entire genome.

\section{Assessing functional annotation with enrichment analyses} Enrichment analyses based on the hypergeometric distribution were carried out in order to assess whether our T2DM candidate list is over-represented with respect to a certain functional category (Table 4). Categories on the physiological level comprise three major pathway resources (KEGG, Reactome, BioCyc) [28-30] and the GO tree [27]. Altogether, we have analyzed 4,555 gene sets, whereof $314(6.9 \%)$ are significant with a P-value below 0.05 [see Additional file 3].

As greater parts of the metabolism are affected by T2DM, multiple pathways have a significant enrichment P-value. For example, in KEGG 45 out of 182 pathways have a Pvalue lower than 0.05 . Table 5 shows the results of pathways with a P-value lower than 1.0E-04. Results for different pathways are not independent. For example, the 136 genes annotated with 'Insulin signaling pathway' and the 46 genes annotated with 'type II diabetes mellitus' share 32 genes. The first four pathways help to validate our significant gene set. 'PPAR signaling', 'Adipocytokine signaling' and 'Insulin signaling pathway' are well related to T2DM.
Since we used several pathway resources in parallel, we can compare the findings for consistency, assuming the resources are independent. For example, we found enrichment of the KEGG pathway 'Fatty acid metabolism' what is complemented by the BioCyc pathways 'fatty acid elongation - saturated', 'fatty acid elongation - unsaturated' and by the GO categories 'positive regulation of fatty acid biosynthesis', 'positive regulation of fatty acid metabolism', 'fatty acid binding' and 'fatty acid oxidation'. The KEGG pathway 'Complement and coagulation cascades' is complemented by the Reactome pathways 'Initial triggering of complement', 'Complement cascade' and the GO categories 'defense response' and 'complement activation, alternative pathway'.

For 116 T2DM gene candidates there is information on the associated biochemical pathways according to the KEGG database. Whereas most genes (106) are associated with a single or a few (up to five) pathways, some genes exhibit a higher interconnection such as Mapk1 (22 pathways), Pik3r1 (19), Aldh9a1 (15), Mapk9 (11), Sh3glb1 (9), Pla2q12a (9), Pkm2, Nfkbia, Dhrs7, Actb (all 6). The importance of Mapk1, Pik3r1, Rasa1 and Socs2 is also supported by Liu et al. as members of an insulin signaling subnet derived from protein-protein-interactions [24].

In order to identify crosstalk between pathways we scored the pathways according to their counts and their overlap

Table 5: Gene set enrichment of the most significant KEGG pathways.

\begin{tabular}{|c|c|c|c|c|c|c|c|}
\hline Pathway ID & SigSet & Set & Sig & All & P-value & Q-value & Pathway description \\
\hline path:mmu03320 & 13 & 69 & 213 & 15274 & $1.02 \mathrm{E}-\mathrm{II}$ & I.37E-09 & PPAR signaling pathway \\
\hline path:mmu04920 & 12 & 73 & 213 & 15274 & $3.46 \mathrm{E}-10$ & I.66E-08 & Adipocytokine signaling pathway \\
\hline path:mmu04930 & 10 & 44 & 213 & 15274 & $3.69 \mathrm{E}-10$ & $1.66 \mathrm{E}-08$ & Type II diabetes mellitus \\
\hline path:mmu04910 & 13 & 128 & 213 & 15274 & $2.70 \mathrm{E}-08$ & $9.09 \mathrm{E}-07$ & Insulin signaling pathway \\
\hline path:mmu046/2 & 6 & 38 & 213 & 15274 & I.30E-05 & 0.000351 & Antigen processing and presentation \\
\hline path:mmu00280 & 6 & 44 & 213 & 15274 & $3.1 I E-05$ & 0.000697 & Valine, leucine and isoleucine deg. \\
\hline path:mmu04610 & 7 & 67 & 213 & 15274 & $3.98 \mathrm{E}-05$ & 0.000764 & Complement and coagulation casc. \\
\hline
\end{tabular}

All are the genes under consideration, Sig the number of candidate genes, Set is the number of genes in the pathway under study and SigSet the overlap of genes in the pathway and the candidate genes. P-values were computed with the upper tail of the hypergeometric distribution indicating the probability of observing this overlap by chance. $\mathbf{Q}$-values are the multiple testing corrected $\mathbf{P}$-values $[60,61]$. 


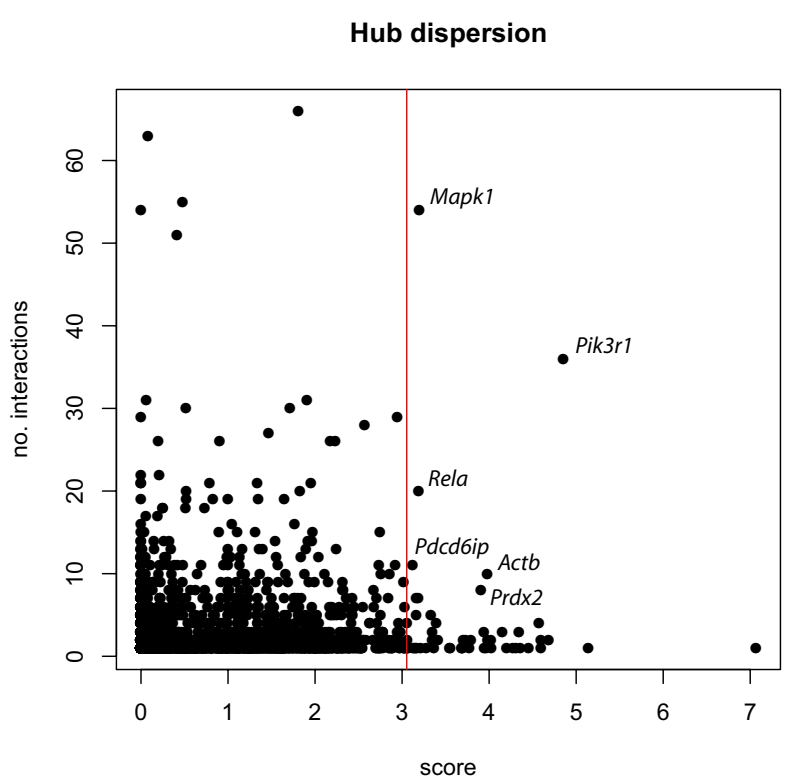

Figure 4

Scatterplot of the number of mouse protein interactions in IntAct and the T2DM gene score. The vertical red line indicates the significance cut-off value of the score. Mapk I and Pik3r I are highlighted as genes with more than 30 interactions.

in the T2DM candidate list (Figure 3). An important module with a large number of genes represented in the T2DM list and a high overlap is visible with the pathways "Insulin signaling", "Type II diabetes mellitus", "PPAR signaling", "Adipocytokine signaling", and "Fatty acid metabolism" pointing to the interplay between obesity and insulin resistance. Another path of signaling action is activation of the RAS/RAF/MEK MAPK cascade resulting in cell growth and gene expression alterations expressed by the crosstalk between "Type II diabetes mellitus" and "MAPK signaling" pathways.

\section{T2DM-related protein-protein interactions}

Protein-protein interactions have been taken from the IntAct database denoting the number of interactions and interactors registered for the T2DM candidate genes. The ratio of interactors to interactions indicates whether the protein participates in big complexes or binds with single proteins. Figure 4 shows the number of interactions and the score for the genes under study. There is no trend for preferential selection of highly interacting genes in our T2DM candidate list. The high-scored genes comprehend a few genes with many interactions like Mapk1, Pik3r1 and Rela in mouse with more than 15 interactions. The large number of interactions of Mapk1 and Pik3r1 is consistent with their participation in many of the signaling pathways (Figure 3). Actb, Cltb, Hspa5 and Grn have more than 600 interactors, indicating big polymers. In human Tsc22d1, Tnfrsf1b, Ndrq1 and Nme1 have most interactions. Lmna is the only gene with more than 300 interactors.

Mapping the interactions on Ensembl genes and coerce the human net and mouse net we derive a graph with 5,179 nodes and 216,446 edges (data not shown). If we consider the edges between significant genes and their non-significant nearest neighbors we still have 1,471 nodes and 11,378 edges. This shows that the disease genes strongly interact with main physiological triggers and deregulate essential parts of the metabolic network. Reducing the interactions on the 213 T2DM genes we end up with 45 nodes and 167 edges [see Figure 4 in Additional file 1].

\section{T2DM-related gene regulatory network}

In order to study the information content of the set of selected disease genes on gene regulation, we have analyzed a) the TFs present in our significant set and b) known target sets of TFs for enrichment. Analysis is often hampered because TFs are known to be expressed at a very low level and fold changes are commonly low. Moreover, many TFs are regulated by phosphorylation (e.g. Foxa's) and/or ligand binding (e.g. Ppar's). As a result, important core regulators including Onecut1 (score 1.2, rank 2461/ 15,277), Hnf4a (2.36, 642/15,277), Tcf1 $(3,243 / 15,277)$, and Foxa2 $(1.4,2055 / 15,277)$ are not in our candidate list.

Collecting TFs from Odom et al. [17,18], TransFac [31] and the GO category GO:0003700 in mouse and human with evidence codes IC, IMP, TAS or IDA we identify 490 TFs. Thereof 12 TFs received a high score in our T2DM set: Srebf1, Tcf2, Rela, Ybx1, Cebpb, Nr1d2, Klf10, Nfil3, Ccrn4l, Atf3, Nme1 and Drap1. Srebf1 and Ybx1 are expressed only in mouse but in every tissue. Cebp's and Srebp's are important regulators of lipid metabolism and adipogenesis and were found differentially expressed in the course of insulin resistance and T2DM. Consistent changes could be identified in the tissues under study (fat: all but Nfil3; liver: Srebf1, Ccrn4l, Ybx1, Bhlhb2, Klf10, Nme1; muscle: Atf3, Klf10, Nme1, Nfil3; pancreatic islets: Corn4l, Atf3, $Y b x 1, B h l h b 2, K l f 10, N m e 1, N f i l 3)$. Pparg is expressed solely in fat where its expression is altered. In total, target sets of 187 TFs have been investigated as gene sets for enrichment analysis. Table 6 shows the TFs from Odom et al. [17] with significant P-value. For example, Cebpa is highly significant. It is expressed in adipose tissue and modulates the expression of leptin. Cebpa shows some correlation with the level of hyperglycemia in [16]. Alteration is also observable in liver. 
Table 6: Gene set enrichment of significant TF target sets from Odom et al. [17].

\begin{tabular}{lllllll}
\hline Transcription factor & SigSet & Set & Sig & All & P-value & Q-value \\
\hline ENSMUSG00000037025:FOXA2 & 33 & 738 & 213 & 15274 & $2.76 \mathrm{E}-09$ & 0.0410 \\
ENSMUSG00000017950:HNF4A & 92 & 3812 & 213 & 15274 & $3.81 \mathrm{E}-09$ & 0.0410 \\
ENSMUSG00000029556:TCFI & 29 & 846 & 213 & 15274 & $6.66 \mathrm{E}-06$ & 0.0410 \\
ENSMUSG00000043013:ONECUTI & 30 & 1096 & 213 & 15274 & 0.000291 & 0.0410 \\
ENSMUSG0000002664I:USFI & 25 & 1290 & 213 & 15274 & 0.0581 & 0.0410 \\
ENSMUSG00000025958:CREBI & 27 & 1794 & 213 & 15274 & 0.366 & 0.0694 \\
\hline
\end{tabular}

The target sets with a P-value below 0.05 are displayed as an extract [see Additional file 3]. Column identifiers as in Table 4.

A gene regulatory network comprising the regulatory interactions of the significant genes and the significant and enriched TFs is shown in Figure 5. Obvious are the five hubs, the core regulatory circuit derived from [17]. Well-regulated candidates can be identified like Acly and Fabp4. Target and regulator at the same time is Ipf1.

\section{Discussion}

The first part of our study was devoted to the identification of genes related to T2DM using different heterogeneous data sources in different organisms. Genes have been scored in each individual study according to their disease relevance and an overall score across the different studies has been computed that reflects their total disease relevance. By this approach we were able to identify 213 genes that have a general disease relevance showing high scores in many different studies as well as genes that have a specific disease relevance expressing high scores in only a few studies.

In the second part of this work the computed T2DM gene set has been used to identify biological networks on different layers of cellular information such as signaling and metabolic pathways, a comprehensive gene regulatory network and protein-protein interactions.

Biological validity of the T2DM candidate set is assessed with a comparison to existing studies and disease gene repositories such as OMIM and genome wide association studies (GWA). The union of the medical reviews $[1,48]$, genetic sources $[2,3,44]$ and the PubMed hits [49] contains 481 genes with an overlap of 64 genes (30\%) to our candidate genes. However, at present only a few genes have been identified through GWA in humans [5-11]. Since the contribution of most of the known risk alleles to the development of type 2 diabetes is rather small, one might conclude that many additional genetic factors are still unknown. Therefore, and since there is no unambiguous set of candidates that defines truly positive disease genes in a polygenic context, our analysis may provide guidance for future systematic investigation of candidate genes and further validation studies. Nevertheless, variants of Pparg and Tcf7l2 have been consistently found in recent GWA for T2DM and appear to be moderately significant in our meta-analysis as well.

It should furthermore be noted that GWA studies themselves show only little overlap. Two recently published meta-analysis studies on GWA [50,51] have an overlap of a single gene, PPARG, which is significant at the 0.01 level in our study.

Our scoring approach is very general. It combines genome-wide transcriptional studies from the Affymetrix GeneChip platform for obesity-induced T2DM, selective previous knowledge as well as gene lists derived from the biomedical literature.

In the study at hand each resource has the same weight in the computation of the score. The entire method, however, could be tuned towards a certain focus by introducing weights and computing weighted scores with weighted random background distributions, for example, if one is particularly interested in a certain tissue or in a certain cellular level of information (transcriptome, gene regulation, proteome). In order to weight the fold changes derived from transcriptome data we have used the information on the reproducibility of the signals (coefficient of variation from replicate experiments) and the information whether the gene is expressed in the study samples or not. We have found that this weighting procedure improves results in comparison to simple fold changes because, for example, genes that are not expressed in the study samples might also show high - but senseless - fold changes adding additional noise to the procedure. Alternative weights could be introduced by taking into account the genetic variation as number of SNPs, or the degree in the protein-protein interaction network to separate major players from redundant genes following the hypothesis, that key factors have to be well-connected.

In our approach we include both, genes with low but consistent expression changes across the different studies as well as strongly differentially expressed genes with respect to a single study. We used entropy as an indicator for measuring generality and specificity of a candidate gene 




\section{Figure 5}

Gene regulatory network composed of the significant genes. Significant TFs and TFs with enriched target sets with respect to the T2DM candidate gene list. Thick ends of the arrows point to TFs, thin ends point to target genes.

with respect to the different studies. The correlation between the score and the entropy is 0.80 [a plot of the entropy versus the score is given in Figure 5 in Additional file 1]. However, most of our T2DM genes have high entropy and, thus, contribute to expression changes in many of the experiments.

Figure 2 reflects a limited overlap of the T2DM genes predicted by this study with those predicted by other bioinformatics methods. This difference can be explained by the differences in the data domain used for the predic- tions (for example, sequence data, gene expression data, PPIs) and differences in the methods themselves. The lack of overlap is not unique to this study and seems to be a common problem with any two prediction studies. In particular, one study - Tiffin et al. - compared seven different analysis methods and found that there was no gene common to all studies [22]. However, it should be noted that using the same data sets different bioinformatics methods are able two find consistent overlap (five and six out of seven studies) as was shown in Tiffin et al. [22]. We explored the pairwise overlap of different T2DM candi- 
date approaches (including our study) [see Additional file 4]. The comparison exhibits two characteristics. Firstly, a common lack of commonality is observable resulting in the different data used and methods applied in the approaches. Secondly, our meta-analysis has a comparable performance with respect to biologically validated gene sets (highlighted rows: GWA and OMIM T2DM genes).

Despite these major sources of variation, there are further differences in analyzing microarray data with respect to chip platform and probe annotation. We have used the remapped probe annotation as provided by the R/Bioconductor software [37] which results in different sizes of the probe sets so that results can be different when using the annotation of the chip provider.

To assess the reliability of using mouse and human gene expression data we have compared the datasets from the two species separately. This analysis has to be stratified for the tissues under study. For human the data sets include skeletal muscle and pancreas. If we reduce mouse data to the same two tissues and perform the score evaluation on the two species separately we end up with 6,173 genes in total in the intersection and a correlation of 0.64 between the two score vectors. The human meta-analysis generates 91 significant genes and the mouse meta-analysis 31 genes. The overlap has 15 genes: Abcc8, Adipoq, Gck, Irs1, Irs2, Irs4, Ptpn1, Slc2a2, Lpl, Pik3r1, Tcf1, Retn, Serpine1, $R b p 4, B 2 m$.

A common approach in meta-analyses is to apply the same statistical test to congeneric studies and combine the resulting P-values by the Fisher method or Z-Score. We found this not practicable in our case, since the experimental sources are too heterogeneous. An extension to the web tool may open the way to introduce weights, chosen by the user.

To contrast the different data sources a correlation heatmap is provided [see Figure 6 in Additional file 1]. In order to measure the dependency of the scoring method on published data - particularly review papers - we computed the correlation of the scores derived from the qualitative and quantitative data. The correlation is 0.07 indicating that the transcriptome data is rather independent of the published review knowledge. In the 'qualitative' category of our study, comprising reviews/OMIM, knockout models and PubMedGeneRIF [1-3,19,44,47-49], we find 481 genes to be related with the disease. Only a small proportion (64 corresponding to 30\%) of those genes were also found in our T2DM candidate list, so that the computed scores do not replicate literature knowledge to a dominating extent. This does not mean that our results lead to completely different results. Using a leave-one-out



Figure 6

Histogram of gene scores (black line) and background distribution of scores derived from Bootstrap26[26]sampling (blue line). The vertical red line marks the cut-off for the T2DM candidate gene list.

cross-validation with these studies we measured the significance of the overlap of each of these studies with our candidate list. This overlap can be quantified with the Pvalue derived from the upper tail of the hypergeometric distribution [52]. For all of the 'qualitative' reference sets we computed highly significant P-values (for example StumvollGoldstein2005: 7.09E-21, DeanMcEntyre2004: 5.28E-19, OMIM: 6.9E-15, PubMedGeneRIF: 6.73E-16).

Many existing T2DM data sets have not been incorporated in this study. For example, all transcriptome studies that were conducted on other microarray platforms than Affymetrix have been discarded because of compatibility issues. With the recent progress in merging gene expression data this limitation is soon questionable. Furthermore the selected data sets have a certain bias towards obesity-induced T2DM what is somewhat justified since obesity is a major risk factor. However, our study can be easily extended with additional sources of T2DM-relevant information. On the genetic level the results of QTL studies or, in human, association studies would upgrade the genetic component of the meta-analysis. Likewise to the OMIM source a sequence change does not necessarily lead to detection by expression change or a different criteria used in the study. E.g. a misfolded protein is not identifiable in this approach. 
Furthermore, valuable information would be results from proteomic or metabolomic studies, but unfortunately data is still very sparse. Although the meta-analysis approach detects disease and candidate genes, it fails for some very specific well-known candidates. If a gene is only active at a medium level in only one tissue it will hardly be in our list. For example, Pparg (score 2.53, rank $500 / 15,277)$ is mainly expressed in fat tissue. Our general approach with a restrictive cut-off favors genes with either a consistent or a very strong alteration. However, with a less restrictive cut-off at the 0.01-quantil of the score we retrieve most of the known genes, but would increase the number of false positives to a high extent.

A simple enrichment analysis based on the hypergeometric distribution has been applied in order to characterize the T2DM set on the network level including pathways, regulatory networks and protein-protein interactions. In general, we find a high consistency of the results of the enrichment analysis when screening different databases. For enrichment we used a hypergeometric test and multiple testing corrections based on Q-values to keep the results comparable between the different databases. Alternative approaches might be useful if focusing on specific annotation. Particularly, for the GO database this approach does not take into account the specific graph structure. Furthermore, there is no unique structure available in the pathway databases. Here, for example up- or downregulation of the involved genes and control of the fluxes are important features and could be used to stratify the enrichment.

Protein-protein interactions are still very sparse or derived from high-throughput experiments with low overlap and low reproducibility so that results have to be carefully cross-checked. For example, we find a protein complex arising from one experiment of Collins et al. [53] with vague relationship to T2DM in the network of the candidate genes.

The gene regulatory network associated with the T2DM candidate set is generic in the sense that all interactions are displayed regardless whether the genes are expressed in a specific tissue or not. This network can be tuned towards tissue specificity by taking into account tissuespecific gene expression and other characteristics. Using tissue expression data sets [54] we can assess the representation of the different tissues in our T2DM candidate list. A total of 197 genes from the list are included in the tissue expression panel [41], where $140(71 \%)$ are expressed in fat, $96(49 \%)$ in muscle and $90(46 \%)$ in liver. An intersection of $31 \%$ is expressed in all three tissues (data not shown).
There are further limitations in analyzing gene regulatory networks. Information of TF binding sites - besides computationally predicted sites - is sparse and the knowledge on target sets of TFs is limited. In Table 6 the P-values for six target sets of regulators are listed that have been derived from ChIP on Chip data. The Chip on Chip data might also help characterizing the 128 unknown T2DM genes as being potential TF targets. The overlap between this uncharacterized subset and the TF target sets are: Hnf 4 a 50 genes, Foxa 13 genes, Usf1 19 genes, Tcf1 11 genes, Creb1 19 genes and Onecut1 11 genes. However, this technique is still error-prone and generates a lot of false positive targets due to the different steps in the experiment. Commonly, we end up with large targets sets containing thousands of genes $[17,18]$. Here, new methods of computational analysis that combine ChIP on Chip-predicted targets with sequence analysis of their promoter regions have to be developed.

\section{Conclusion}

We have identified a core set of 213 T2DM candidate genes by a meta-analysis of existing data sources. We have explored the relation of these genes to disease relevant information and - using enrichment analysis - we have identified biological networks on different layers of cellular information such as signaling and metabolic pathways, gene regulatory networks and protein-protein interactions.

\section{Methods}

\section{Selection and integration of T2DM resources}

Data sets were selected from heterogeneous sources that target different levels of cellular information. For each gene and each source we computed a numerical value that expresses its likelihood for being T2DM relevant. Data categories are either binary or quantitative.

Binary data was introduced by incorporating medical reviews, phenotype information (for example from knock-out genes), results from proteome analysis [1$3,19,44,48,49$ ] as well as published candidate gene lists from previous studies or models $[22,23,47,55]$. Binary information was assigned according to the fact whether the gene had been identified in the study or not.

Quantitative data was incorporated by evaluating data from differential gene expression and time series microarray studies [12-16]. In order to extract comparable information across the different studies we used data from the same technological platform (Affymetrix GeneChip studies). Furthermore, in order to conduct standardized data normalization (see below) only studies were taken into account that published and provided the raw data (CEL file level) [see Additional file 5]. 
Genes do not act as individual units, they collaborate in overlapping pathways, the deregulation of which is a hallmark for the disease under study. In order to integrate pathway information and to derive cellular network information on the selected genes, we added functional annotation from pathway databases such as KEGG, Reactome, BioCyc [28-30], GO [27], protein-protein interaction databases such as IntAct [56] and databases on transcription factors (TFs) such as TRANSFAC [31].

Genetic variation of a gene was described with the number of associated SNPs. The number of SNPs in the coding and surrounding region of the gene is noted for mouse and human [57]. A particular biomedical interest is on genes that can be used for drug development. This characteristic has been previously assigned to the gene's ability to provide binding sites for biochemical well-characterized (i.e. druggable) compounds [58,59]. The selected candidates were evaluated with respect to this information. All collected information on the identified 213 T2DM candidate genes and further description of the data sets is given [see Additional file 2].

\section{Mapping of gene IDs}

A central pre-requisite of any meta-analysis approach is the consolidation of the different ID types, for example coming from different organisms and from different versions of chips. We have used the Ensembl database [57] as the backbone annotation for all studies. IDs are mapped on their mouse Ensembl gene ID (version 41). Mapping and merging of the information has been done within $\mathrm{R}$ and the BioConductor package collection [33,34]. To ease the access for researchers we have added the more informative MGI marker symbols and HUGO ID's together with ENTREZ gene numbers and RefSeq IDs. In total, information on 15,277 Ensembl annotated genes has been mapped.

\section{Transcriptome data pre-processing and normalization}

Affymetrix gene chip annotations were adapted from latest genome annotations [37] in version 8. Affymetrix data has been normalized with GC RMA using the R/BioConductor software platform [36]. For transcriptome studies that are targeting differential expression three bits of information are stored - the fold-change indicating the alteration of the gene when comparing the diabetic state with the normal state, the standard error of the fold-change computed from the replicated experiments in that study and the expression P-value (presence-call) that indicates whether or not the gene is expressed in the target samples under study. In time series studies we store the correlation between phenotypic characteristics, for example blood glucose, and the gene expression levels with the coefficient of variation and the expression P-value.

\section{Scoring T2DM relevance of genes across studies}

In order to score the different categories of information, i.e. binary counts and quantitative gene expression values, for each category we summarized the scores of the individual experiments. For binary information the counts were grouped in sub-categories, for example knock-out mice described in two reviews only get a single count.

For quantitative information, the score of the $i$ th gene in the $j$ th study, $s_{i j}$, was computed as follows:

$s_{i j}=\left\{\begin{array}{cc}\left|\log 2\left(r_{i j}\right)\right|\left(1-\frac{e_{i j}}{r_{i j}}\right)\left(1-p_{i j}\right), & p_{i j} \leq 0.1 \text { and } e_{i j} / r_{i j} \leq 1 \\ 0, & \text { else }\end{array}\right.$.

Here, $r_{i j}$ is the fold change, $p_{i j}$ is the average detection Pvalue and $e_{i j}$ is the standard error of the ratio derived from the experimental replicates of the study. Thus, the fold change is weighted with its reproducibility across the experimental replicates and with the likelihood of the gene being expressed in the study's target samples. A similar formula applies for correlation studies:

$$
s_{i j}=\left\{\begin{array}{cc}
\left|c_{i j}\right|\left(1-v_{i j}\right)\left(1-p_{i j}\right), & p_{i j} \leq 0.1 \text { and } v_{i j} \leq 1 \\
0, & \text { else }
\end{array} .\right.
$$

Here, $c_{i j}$ is the correlation to a certain phenotypic parameter, $v_{i j}$ the coefficient of variation of the gene's signal across experimental replicas. The formula is applied on the data of Nadler et al. [16]. Mice from three different strains (B6, BTBR and F2 intercrosses) are separated in five classes with increasing hyperglycemia. The Kendall rank correlation between the classes and the gene expression was calculated.

The total score of the gene was computed as the sum across all individual study scores.

\section{Sampling for significance}

In order to assess the significance of the overall gene scores we generated random gene scores. For this bootstrap [26] we draw a random score from each study. The sum of the drawn study scores determines the score for a virtual gene. The distributions of the original scores (black line) and the random scores (blue line) are shown in Figure 6 . Using the random distribution as background sample we assigned those genes as "significant" that are above the 99.9 percentile of the background distribution.

\section{Accounting for experimental study bias}

For each gene, entropy of the score distribution was computed in order to quantify the relative influence of a certain study (for example a particular tissue) on the overall 
score. Let $s_{i j}$ be the score of the $i$ th gene in the jth study, then $E_{i}$ is a measure for the uniformity of the score distribution over the individual experiments:

$$
E_{i}=-\sum_{j} \frac{s_{i j}}{\sum_{k} s_{i k}} \log _{2}\left(\frac{s_{i j}}{\sum_{k} s_{i k}}\right)
$$

Entropy is low if a single study has a major contribution on the overall score. On the other hand, entropy is high if most of the studies account equally for the score. A plot of the entropy versus the score is given in Figure 5 in Additional file 1.

\section{Identification of disease related networks using enrichment analyses}

Disease related networks were investigated with four different types of network information - biological pathways [28-30], protein-protein interaction networks [56], gene regulatory networks $[17,18,31]$ and functional annotation using GO annotations [27] (see Table 4). These networks define - by annotation - groups of associated genes. The hypergeometric distribution compares the overlap between our superset and the gene group to the overlap of a random selection of two gene sets with the same size [52]. Thus we were able to assign each annotation item (pathway, GO term etc.) a P-value that reflects enriched occurrence of candidate genes. In case of GO terms we include only genes with evidence codes IC, IMP, TAS or IDA to rely on the same confidence level as in the above mentioned resources. We correct P-values for multiple testing using Q-values following Storey for the control of the false discovery rate $[60,61]$.

The same method we use in the leave-one-out cross-validation. Our qualitative studies are the benchmark for our scoring approach. The scoring, including a notional candidate set, is calculated without the respective qualitative study. The hypergeometric distribution of the qualitative study gene set and the notional candidate set assigns a Pvalue. This P-value reflects the success of the score to identify the genes from the qualitative study.

\section{Abbreviations}

T2DM: type-2 diabetes mellitus; GO: gene ontology; TF: transcription factor; ID: identifier; SNP: single nucleotide polymorphism; GWA: genome-wide association.

\section{Authors' contributions}

AR collected and processed the data, implemented and conducted the meta-analysis and wrote the manuscript. HA-H contributed with biological interpretation of the results and with writing the manuscript. $\mathrm{RH}$ designed and led the study, performed data analysis and contributed to the manuscript.

\section{Additional material}

\author{
Additional file 1 \\ Additional figures. Supplementary figures for the manuscript. \\ Click here for file \\ [http://www.biomedcentral.com/content/supplementary/1471- \\ 2164-9-310-S1.pdf]
}

\section{Additional file 2}

Candidate genes. A tabular version of the web tool data for the T2DM candidate gene list of 213 genes.

Click here for file

[http://www.biomedcentral.com/content/supplementary/1471-

2164-9-310-S2.xls]

\section{Additional file 3}

Significant categories. The significant categories of the enrichment analysis.

Click here for file

[http://www.biomedcentral.com/content/supplementary/1471-

2164-9-310-S3.txt]

\section{Additional file 4}

Overlap of different candidate gene sets. A table showing the overlap of different candidate gene sets for T2DM.

Click here for file

[http://www.biomedcentral.com/content/supplementary/1471-

2164-9-310-S4.pdf]

\section{Additional file 5}

Source description. Describing the sources of information used in the web tool and [Additional file 1].

Click here for file

[http://www.biomedcentral.com/content/supplementary/14712164-9-310-S5.pdf]

\section{Acknowledgements}

Christoph Wierling and Atanas Kamburov retrieved and edited the pathway data. André Rauschenbach and Anja Thormann developed the web tool.

The work was in part funded by the German Federal Ministry of Education and Research with the BioProfile Nutrigenomics grant "PhysioSim" (FKZ 313325 ), by the European Union under its $6^{\text {th }}$ Framework Programme with the grant SysProt (LSHG-CT-2006-037457), grant number

(NGFNOIGS082 I/0 I GS0487) and by the Max Planck Society.

\section{References}

I. Stumvoll M, Goldstein BJ, Haeften TW: Type 2 diabetes: principles of pathogenesis and therapy. The Lancet 2005, 365:1333-1346.

2. Jackson Labs: Human Disease and Mouse Model Detail for NIDDM.

3. Nandi A, Kitamura Y, Kahn CR, Accili D: Mouse models of insulin resistance. Physiol Rev 2004, 84(2):623-647.

4. Clee SM, Attie AD: The genetic landscape of type 2 diabetes in mice. Endocr Rev 2007, 28(I):48-83. 
5. Frayling TM, Timpson NJ, Weedon MN, Zeggini E, Freathy RM, Lindgren CM, Perry JR, Elliott KS, Lango H, Rayner NW, Shields B, Harries LW, Barrett JC, Ellard S, Groves CJ, Knight B, Patch AM, Ness AR, Ebrahim S, Lawlor DA, Ring SM, Ben-Shlomo Y, Jarvelin MR, Sovio U, Bennett AJ, Melzer D, Ferrucci L, Loos RJ, Barroso I, Wareham NJ, Karpe F, Owen KR, Cardon LR, Walker M, Hitman GA, Palmer CN, Doney AS, Morris AD, Smith GD, Hattersley AT, McCarthy MI: A common variant in the FTO gene is associated with body mass index and predisposes to childhood and adult obesity. Science 2007, 3 | 6(5826):889-894.

6. Grant SFA, Thorleifsson G, Reynisdottir I, Benediktsson R, Manolescu A, Sainz J, Helgason A, Stefansson H, Emilsson V, Helgadottir A, Styrkarsdottir U, Magnusson KP, Walters GB, Palsdottir E, Jonsdottir T, Gudmundsdottir T, Gylfason A, Saemundsdottir J, Wilensky RL, Reilly MP, Rader DJ, Bagger Y, Christiansen C, Gudnason V, Sigurdsson G, Thorsteinsdottir U, Gulcher JR, Kong A, Stefansson K: Variant of transcription factor 7-like 2 (TCF7L2) gene confers risk of type 2 diabetes. Nat Genet 2006, 38(3):320-323.

7. Saxena R, Voight BF, Lyssenko V, Burtt NP, de Bakker PI, Chen H, Roix J], Kathiresan S, Hirschhorn JN, Daly MJ, Hughes TE, Groop L, Altshuler D, Almgren P, Florez JC, Meyer J, Ardlie K, Bengtsson K, Isomaa B, Lettre G, Lindblad U, Lyon HN, Melander O, Newton-Cheh C. Nilsson P, Orho-Melander M, Rastam L, Speliotes EK, Taskinen MR, Tuomi T, Guiducci C, Berglund A, Carlson J, Gianniny L, Hackett R, Hall L, Holmkvist J, Laurila E, Sjogren M, Sterner M, Surti A, Svensson M, Svensson M, Tewhey R, Blumenstiel B, Parkin M, Defelice M, Barry R, Brodeur W, Camarata J, Chia N, Fava M, Gibbons J, Handsaker B, Healy C, Nguyen K, Gates C, Sougnez C, Gage D, Nizzari M, Gabriel SB, Chirn GW, Ma Q, Parikh H, Richardson D, Ricke D, Purcell S: Genome-Wide Association Analysis Identifies Loci for Type 2 Diabetes and Triglyceride Levels. Science 2007.

8. Scott LJ, Mohlke KL, Bonnycastle LL, Willer CJ, Li Y, Duren WL, Erdos MR, Stringham HM, Chines PS, Jackson AU, Prokunina-Olsson L, Ding C], Swift AJ, Narisu N, Hu T, Pruim R, Xiao R, Li XY, Conneely KN, Riebow NL, Sprau AG, Tong M, White PP, Hetrick KN, Barnhart MW, Bark CW, Goldstein JL, Watkins L, Xiang F, Saramies J, Buchanan TA, Watanabe RM, Valle TT, Kinnunen L, Abecasis GR, Pugh EW, Doheny KF, Bergman RN, Tuomilehto J, Collins FS, Boehnke M: A Genome-Wide Association Study of Type 2 Diabetes in Finns Detects Multiple Susceptibility Variants. Science 2007, 3 16: | $34 \mid-5$.

9. Sladek R, Rocheleau G, Rung J, Dina C, Shen L, Serre D, Boutin P, Vincent D, Belisle A, Hadjadj S, Balkau B, Heude B, Charpentier G, Hudson TJ, Montpetit A, Pshezhetsky AV, Prentki M, Posner BI, Balding DJ, Meyre D, Polychronakos C, Froguel P: A genome-wide association study identifies novel risk loci for type 2 diabetes. Nature 2007, 445(7|30):88I-885.

10. Steinthorsdottir V, Thorleifsson G, Reynisdottir I, Benediktsson R, Jonsdottir T, Walters GB, Styrkarsdottir U, Gretarsdottir S, Emilsson $\checkmark$, Ghosh S, Baker A, Snorradottir S, Bjarnason H, Ng MC, Hansen T, Bagger Y, Wilensky RL, Reilly MP, Adeyemo A, Chen Y, Zhou J, Gudnason V, Chen G, Huang H, Lashley K, Doumatey A, So WY, Ma RC, Andersen G, Borch-Johnsen K, Jorgensen T, van Vliet-Ostaptchouk JV, Hofker MH, Wijmenga C, Christiansen C, Rader DJ, Rotimi C, Gurney M, Chan JC, Pedersen O, Sigurdsson G, Gulcher JR, Thorsteinsdottir $U$, Kong A, Stefansson K: A variant in CDKALI influences insulin response and risk of type 2 diabetes. Nat Genet 2007, 39:770-5.

II. Zeggini E, Weedon MN, Lindgren CM, Frayling TM, Elliott KS, Lango $H$, Timpson NJ, Perry JR, Rayner NW, Freathy RM, Barrett JC, Shields B, Morris AP, Ellard S, Groves C], Harries LW, Marchini JL, Owen KR, Knight B, Cardon LR, Walker M, Hitman GA, Morris AD, Doney AS, McCarthy MI, Hattersley AT: Replication of Genome-Wide Association Signals in U.K. Samples Reveals Risk Loci for Type 2 Diabetes. Science 2007.

12. Gunton JE, Kulkarni RN, Yim S, Okada T, Hawthorne WJ, Tseng YH, Roberson RS, Ricordi C, O'Connell PJ, Gonzalez FJ, Kahn CR: Loss of ARNT/HIF Ibeta mediates altered gene expression and pancreatic-islet dysfunction in human type 2 diabetes. Cell 2005, I 22(3):337-349.

13. Mootha VK, Lindgren CM, Eriksson KF, Subramanian A, Sihag S, Lehar J, Puigserver P, Carlsson E, Ridderstrale M, Laurila E, Houstis N, Daly MJ, Patterson N, Mesirov JP, Golub TR, Tamayo P, Spiegelman B, Lander ES, Hirschhorn JN, Altshuler D, Groop LC: PGC-I alpharesponsive genes involved in oxidative phosphorylation are coordinately downregulated in human diabetes. Nat Genet 2003, 34(3):267-273.

14. Biddinger SB, Almind K, Miyazaki M, Kokkotou E, Ntambi JM, Kahn $C R$ : Effects of diet and genetic background on sterol regulatory element-binding protein-I c, stearoyl-CoA desaturase I, and the development of the metabolic syndrome. Diabetes 2005, 54(5): |3|4-|323.

15. Lan H, Rabaglia ME, Stoehr JP, Nadler ST, Schueler KL, Zou F, Yandell BS, Attie AD: Gene Expression Profiles of Nondiabetic and Diabetic Obese Mice Suggest a Role of Hepatic Lipogenic Capacity in Diabetes Susceptibility. Diabetes 2003, 52(3):688-700.

16. Nadler ST, Stoehr JP, Schueler KL, Tanimoto G, Yandell BS, Attie AD: The expression of adipogenic genes is decreased in obesity and diabetes mellitus. PNAS 2000, 97(21): | I37|-II376.

17. Odom DT, Dowell RD, Jacobsen ES, Nekludova L, Rolfe PA, Danford TW, Gifford DK, Fraenkel E, Bell GI, Young RA: Core transcriptional regulatory circuitry in human hepatocytes. Mol Syst Biol 2006, 2:2006 0017 .

18. Odom DT, Zizlsperger N, Gordon DB, Bell GW, Rinaldi NJ, Murray HL, Volkert TL, Schreiber J, Rolfe PA, Gifford DK, Fraenkel E, Bell GI, Young RA: Control of pancreas and liver gene expression by HNF transcription factors. Science 2004, 303(5662): | 378- | $38 \mid$.

19. Chen XC S.W. and Pannell, L.K. and Hess, S.: Quantitative Proteomic Analysis of the Secretory Proteins from Rat Adipose Cells Using a 2D Liquid Chromatography-MS/MS Approach. J Proteome Res 2005, 4(2):570-577.

20. Rhodes DR, Yu J, Shanker K, Deshpande N, Varambally R, Ghosh D, Barrette T, Pandey A, Chinnaiyan AM: Large-scale meta-analysis of cancer microarray data identifies common transcriptional profiles of neoplastic transformation and progression. Proc Natl Acad Sci U S A 2004, I 1 (25):9309-93। 4.

21. Bertram L, McQueen MB, Mullin K, Blacker D, Tanzi RE: Systematic meta-analyses of Alzheimer disease genetic association studies: the AlzGene database. Nat Genet 2007, 39(I):17-23.

22. Tiffin N, Adie E, Turner F, Brunner HG, van Driel MA, Oti M, LopezBigas N, Ouzounis C, Perez-Iratxeta C, Andrade-Navarro MA, Adeyemo A, Patti ME, Semple CA, Hide W: Computational disease gene identification: a concert of methods prioritizes type 2 diabetes and obesity candidate genes. Nucleic Acids Res 2006, 34(1 0):3067-308I.

23. mult.: Diabetes Genome Anatomy Project. [http://www.diabe tesgenome.org/].

24. Liu M, Liberzon A, Kong SW, Lai WR, Park PJ, Kohane IS, Kasif S: Network-based analysis of affected biological processes in type 2 diabetes models. PLoS genetics 2007, 3(6): 96.

25. Sun G: Application of DNA microarrays in the study of human obesity and type 2 diabetes. Omics 2007, I I (I):25-40.

26. Bradley E: Bootstrap Methods: Another Look at the Jackknife. 1979, 7(I): I-27.

27. Ashburner M, Ball CA, Blake JA, Botstein D, Butler H, Cherry JM, Davis AP, Dolinski K, Dwight SS, Eppig JT, Harris MA, Hill DP, IsselTarver L, Kasarskis A, Lewis S, Matese JC, Richardson JE, Ringwald M, Rubin GM, Sherlock G: Gene Ontology: tool for the unification of biology. Nature Genetics 2000, 25:25-29.

28. Joshi-Tope G, Gillespie M, Vastrik I, DEustachio P, Schmidt E, Bono B, Jassal B, Gopinath GR, Wu GR, Matthews L, Lewis S, Birney E, Stein L: Reactome: a knowledgebase of biological pathways. Nucl Acids Res 2005, 33:D428-432.

29. Kanehisa M, Goto S: KEGG: Kyoto Encyclopedia of Genes and Genomes. Nucleic Acids Research 2000, 28(I):27-30.

30. Romero P, Wagg J, Green ML, Kaiser D, Krummenacker M, Karp PD: Computational prediction of human metabolic pathways from the complete human genome. Genome Biology 2004, 6:R2.

3I. Matys V, Kel-Margoulis OV, Fricke E, Liebich I, Land S, Barre-Dirrie A, Reuter I, Chekmenev D, Krull M, Hornischer K, Voss N, Stegmaier P, Lewicki-Potapov B, Saxel H, Kel AE, Wingender E: TRANSFAC and its module TRANSCompel: transcriptional gene regulation in eukaryotes. Nucleic Acids Res 2006, 34(Database issue):DI08-10.

32. Gentleman R: geneplotter: Graphics related functions for Bioconductor. 2006.

33. Gentleman RC, Carey VJ, Bates DM, Bolstad B, Dettling M, Dudoit S, Ellis B, Gautier L, Ge Y, Gentry J, Hornik K, Hothorn T, Huber W, lacus S, Irizarry R, Li FLC, Maechler M, Rossini AJ, Sawitzki G, Smith C, Smyth G, Tierney L, Yang JYH, Zhang J: Bioconductor: Open 
software development for computational biology and bioinformatics. Genome Biology 2004, 5:R80.

34. R Development Core Team: R: A Language and Environment for Statistical Computing. Vienna, Austria , R Foundation for Statistical Computing; 2005.

35. T2DM-GeneMiner [http://t2dm-geneminer.molgen.mpg.de]

36. Wu Z, Irizarry RA, Gentleman R, Murillo FM, Spencer F: A Model Based Background Adjustment for Oligonucleotide Expression Arrays. Johns Hopkins University, Dept of Biostatistics Working Papers 2004

37. Dai M, Wang P, Boyd AD, Kostov G, Athey B, Jones EG, Bunney WE, Myers RM, Speed TP, Akil H, Watson SJ, Meng F: Evolving gene/ transcript definitions significantly alter the interpretation of GeneChip data. Nucleic Acids Res 2005, 33(20): el 75.

38. Gu HF, Abulaiti A, Ostenson CG, Humphreys K, Wahlestedt C Brookes AJ, Efendic S: Single nucleotide polymorphisms in the proximal promoter region of the adiponectin (APMI) gene are associated with type 2 diabetes in Swedish caucasians. Diabetes 2004, 53 SuppI I:S3I-5.

39. Delaigle AM, Senou M, Guiot Y, Many MC, Brichard SM: Induction of adiponectin in skeletal muscle of type 2 diabetic mice: In vivo and in vitro studies. Diabetologia 2006, 49(6): | 3||$-\mid 323$.

40. Masuzaki H, Paterson J, Shinyama H, Morton NM, Mullins J], Seckl JR, Flier JS: A transgenic model of visceral obesity and the metabolic syndrome. Science 200I, 294(5549):2166-2I 70 .

4I. Toye AA, Lippiat JD, Proks P, Shimomura K, Bentley L, Hugill A, Mijat V, Goldsworthy M, Moir L, Haynes A, Quarterman J, Freeman HC Ashcroft FM, Cox RD: A genetic and physiological study of impaired glucose homeostasis control in C57BL/6J mice. Diabetologia 2005, 48(4):675-686.

42. Freeman HC, Hugill A, Dear NT, Ashcroft FM, Cox RD: Deletion of nicotinamide nucleotide transhydrogenase: a new quantitive trait locus accounting for glucose intolerance in C57BL/6 mice. Diabetes 2006, 55(7):2153-2156.

43. Hoek JB, Rydstrom J: Physiological roles of nicotinamide nucleotide transhydrogenase. Biochem J 1988, 254(I): I-IO.

44. OMIM: Online Mendelian Inheritance in Man, OMIM (TM). :MIM Number: 125853: 12.06.2006 [http://www.ncbi.nlm.nih.gov/ omim/].

45. Steppan CM, Bailey ST, Bhat S, Brown EJ, Banerjee RR, Wright CM, Patel HR, Ahima RS, Lazar MA: The hormone resistin links obesity to diabetes. Nature 200I, 409(68I8):307-3/2

46. Youn BS, Yu KY, Park HJ, Lee NS, Min SS, Youn MY, Cho YM, Park YJ, Kim SY, Lee HK, Park KS: Plasma resistin concentrations measured by enzyme-linked immunosorbent assay using a newly developed monoclonal antibody are elevated in individuals with type 2 diabetes mellitus. J Clin Endocrinol Metab 2004, 89(I): 150-156.

47. Parikh H, Groop L: Candidate genes for type $\mathbf{2}$ diabetes. Rev Endocr Metab Disord 2004, 5(2): I5 I- 176.

48. Dean L, McEntyre J: The Genetic Landscape of Diabetes. NCBI; 2004

49. Mitchell JA, Aronson AR, Mork JG, Folk LC, Humphrey SM, Ward JM: Gene indexing: characterization and analysis of NLM's GeneRIFs. AMIA Annu Symp Proc 2003:460-464

50. Frayling TM: Genome-wide association studies provide new insights into type 2 diabetes aetiology. Nature reviews 2007, 8(9):657-662.

5I. Zeggini E, Scott LJ, Saxena R, Voight BF, Marchini JL, Hu T, de Bakker $\mathrm{PI}$, Abecasis GR, Almgren P, Andersen G, Ardlie K, Bostrom KB, Bergman RN, Bonnycastle LL, Borch-Johnsen K, Burtt NP, Chen H, Chines PS, Daly MJ, Deodhar P, Ding C], Doney AS, Duren WL, Elliott KS, Erdos MR, Frayling TM, Freathy RM, Gianniny L, Grallert H Grarup N, Groves C], Guiducci C, Hansen T, Herder C, Hitman GA, Hughes $T E$, Isomaa $B$, Jackson $A U$, Jorgensen $T$, Kong $A$, Kubalanza $K$, Kuruvilla FG, Kuusisto J, Langenberg C, Lango $H$, Lauritzen T, Li Y, Lindgren CM, Lyssenko $V$, Marvelle AF, Meisinger C, Midthjell $K$, Mohlke KL, Morken MA, Morris AD, Narisu N, Nilsson P, Owen KR, Palmer CN, Payne F, Perry JR, Pettersen E, Platou C, Prokopenko I, Qi L, Qin L, Rayner NW, Rees M, Roix Jl, Sandbaek A, Shields B, Sjogren M, Steinthorsdottir V, Stringham HM, Swift AJ, Thorleifsson G, Thorsteinsdottir U, Timpson NJ, Tuomi T, Tuomilehto J, Walker M, Watanabe RM, Weedon MN, Willer CJ, Illig T, Hveem K, Hu FB, Laakso M, Stefansson K, Pedersen O, Wareham NJ, Barroso I, Hattersley AT, Collins FS, Groop L, McCarthy MI, Boehnke M, Altshuler $D$ : Meta-analysis of genome-wide association data and large- scale replication identifies additional susceptibility loci for type 2 diabetes. Nat Genet 2008, 40(5):638-645.

52. Klipp E, Herwig R, Kowald A, Wierling C, Lehrach H: Systems Biology in Practice. Wiley- $\mathrm{VCH} ; 2005$.

53. Collins MO, Husi H, Yu L, Brandon JM, Anderson CN, Blackstock WP, Choudhary JS, Grant SG: Molecular characterization and comparison of the components and multiprotein complexes in the postsynaptic proteome. J Neurochem 2006, 97 Suppl I: 16-23.

54. Su Al, Cooke MP, Ching KA, Hakak Y, Walker JR, Wiltshire T, Orth AP, Vega RG, Sapinoso LM, Moqrich A: Large-scale analysis of the human and mouse transcriptomes. National Acad Sciences; 2002:12025199.

55. Kitano H, Oda K, Kimura T, Matsuoka Y, Csete M, Doyle J, Muramatsu M: Metabolic syndrome and robustness tradeoffs. Diabetes 2004, 53 Suppl 3:S6-SI5.

56. Hermjakob H, Montecchi-Palazzi L, Lewington C, Mudali S, Kerrien S, Orchard S, Vingron M, Roechert B, Roepstorff P, Valencia A, Margalit H, Armstrong J, Bairoch A, Cesareni G, Sherman D, Apweiler R: IntAct: an open source molecular interaction database. Nucleic Acids Res 2004, 32(Database issue):D452-5.

57. Birney E, Andrews D, Caccamo M, Chen Y, Clarke L, Coates G, Cox T, Cunningham F, Curwen V, Cutts T, Down T, Durbin R, FernandezSuarez XM, Flicek P, Graf S, Hammond M, Herrero J, Howe K, lyer V, Jekosch K, Kahari A, Kasprzyk A, Keefe D, Kokocinski F, Kulesha E, London D, Longden I, Melsopp C, Meidl P, Overduin B, Parker A, Proctor G, Prlic A, Rae M, Rios D, Redmond S, Schuster M, Sealy I, Searle S, Severin J, Slater G, Smedley D, Smith J, Stabenau A, Stalker J, Trevanion S, Ureta-Vidal A, Vogel J, White S, Woodwark C, Hubbard TJ: Ensembl 2006. Nucleic Acids Res 2006, 34(Database issue): D556-6I.

58. Hopkins AL, Groom CR: The druggable genome. Nat Rev Drug Discov 2002, I(9):727-730.

59. Russ AP, Lampel S: The druggable genome: an update. Drug Discov Today 2005, 10(23-24): 1607-1610

60. Storey JD: A direct approach to false discovery rates. Volume 64. Issue 3 Blackwell Synergy; 2002:479-498.

6I. Storey JD, Taylor JE, Siegmund D: Strong control, conservative point estimation and simultaneous conservative consistency of false discovery rates: a unified approach. Volume 66. Issue I Blackwell Synergy; 2004:187-205

62. open source graph visualization software [http://www.graph viz.org]
Publish with BioMed Central and every scientist can read your work free of charge

"BioMed Central will be the most significant development for disseminating the results of biomedical research in our lifetime. "

Sir Paul Nurse, Cancer Research UK

Your research papers will be:

- available free of charge to the entire biomedical community

- peer reviewed and published immediately upon acceptance

- cited in PubMed and archived on PubMed Central

-yours - you keep the copyright

Submit your manuscript here:

http://www.biomedcentral.com/info/publishing_adv.asp
BioMedcentral 